\title{
Effects of Atrazine on Reproductive Health of Nondiabetic and Diabetic Male Rats
}

\author{
Dinesh Babu Jestadi, Alugoju Phaniendra, Undru Babji, \\ Bhavatharini Shanmuganathan, and Latha Periyasamy \\ Department of Biochemistry and Molecular Biology, School of Life Sciences, Pondicherry University, Puducherry 605 014, India
}

Correspondence should be addressed to Latha Periyasamy; latha.selvamani@yahoo.co.in

Received 27 May 2014; Revised 25 July 2014; Accepted 13 August 2014; Published 28 October 2014

Academic Editor: Hamadi Fetoui

Copyright ( 2014 Dinesh Babu Jestadi et al. This is an open access article distributed under the Creative Commons Attribution License, which permits unrestricted use, distribution, and reproduction in any medium, provided the original work is properly cited.

\begin{abstract}
The aim of the present study was to investigate the effects of low dose of atrazine on reproductive system of male Wistar rats. 16 rats were divided into four groups of four animals each. Group I (nondiabetic) and group III (diabetic) animals served as controls that received safflower oil $(300 \mu \mathrm{L} / \mathrm{kg}$ bw/day), respectively. Group II (nondiabetic) and group IV (diabetic) animals received atrazine $(300 \mu \mathrm{g} / \mathrm{kg}$ bw/day). Nonsignificant decrease in the activities of antioxidant and steroidogenic enzymes and sperm parameters suggests that atrazine did not produce any effect on reproductive system of rats. Histological findings also revealed that atrazine at a dose of $300 \mu \mathrm{g} / \mathrm{kg}$ bw did not produce any testicular toxic effects in nondiabetic and diabetic atrazine treated rats. Low dose of atrazine did not show reproductive toxicity in rats. To know the effects of atrazine in diabetic rats further studies have to be carried out with increased concentration of atrazine.
\end{abstract}

\section{Introduction}

Increased male reproductive abnormalities are due to increased exposure to environmental contaminants such as organochlorine pesticides, poly chlorinated biphenyls, dioxins, phytoestrogens, and other xenoestrogens that enter the human system through food, drinking water, air, and skin contact [1]. Pesticides have been widely used all over the world because they enable the development of agricultural and farming production by controlling a wide range of pests and diseases. However, it is well known that the application of these substances affects human health as well as the environment $[2,3]$. Atrazine (2-chloro-4-ethylamino-6-isopropylamine-1,2,5-triazine: ATZ) is used to control broad-leaf weeds and grasses, for example, corn, sorghum, sugarcane, pineapple, turf, and orchards. ATZ has attracted great attention due to its widespread use and ubiquitous contamination in ground and surface waters, its pattern of use, high persistency, and its potential biological impact in the environment [4]. Atrazine decreases the sperm motility, viability, and count by inducing oxidative stress through the depletion of the antioxidant activities [5, 6]. Atrazine decreases the secretion of follicular stimulating hormone (FSH), luteinizing hormone ( $\mathrm{LH})$, and testosterone concentration by decreasing the weight of pituitary gland and gonadotropin-releasing hormone (GnRH) secretion from hypothalamus [7].

Diabetes mellitus (DM) is a chronic hormonal and metabolic disorder. Globally 366 million people had DM in 2011 and it is expected to rise up to 552 million in 2030. Out of the global diabetic population, $80-90 \%$ diabetic patients are suffering with type 2 diabetes mellitus (T2DM) which caused 4.6 million deaths in 2011 and is expected to reach 439 million in $2030[8,9]$. Etiology of T2DM is very complex and influenced by different factors such as obesity, lack of physical exercise, cigarette smoking, sedentary lifestyle, alcohol consumption, and environmental toxins [8]. In India 50.8 million people have diabetes and it is expected to reach 87 million by the year of 2030 [10]. DM increases oxidative stress by depleting antioxidant activities $[11,12]$. DM suppresses spermatogenesis by reducing hormones such as $\mathrm{FSH}, \mathrm{LH}$, and testosterone and also increases germ cell apoptosis [13].

The aim of the present study was to investigate the possible effects of the low dose of atrazine on reproductive function of nondiabetic and diabetic rats. 


\section{Materials and Methods}

2.1. Chemicals. Atrazine (technical grade 98.8\%) and streptozotocin were purchased from Sigma Aldrich (St. Louis, MO, USA). All the other chemicals used were of analytical grade.

2.2. Animals. 16 Adult male Wistar rats (120-180 g) were procured and housed in plastic suspended cages and fed with normal pelletized chow and water (ad libitum) under standard temperature $\left(24 \pm 3^{\circ} \mathrm{C}\right)$ and photoperiod (12 hours light : 12 hours dark). The experimental animals were handled as per the guidelines of Committee for the Purpose of Control and Supervision of Experiments on Animals (CPCSEA) which were approved by the Institutional Animal Ethics Committee (IAEC approval number: PU/SLS/IAEC/2014/11, dated 20.02.2014) of Pondicherry University, Puducherry, India.

2.3. Induction of Diabetes. High fat diet (HFD: $58 \%$ fat, $25 \%$ protein, and $17 \%$ carbohydrate) was freshly prepared daily in sterile condition with composition of $365 \mathrm{~g}$ normal pelletized rat chow, $310 \mathrm{~g}$ lard oil, $250 \mathrm{~g}$ casein, $10 \mathrm{~g}$ cholesterol, $60 \mathrm{~g}$ vitamin and mineral mix, $3 \mathrm{~g}$ methionine, $1 \mathrm{~g}$ yeast, and $1 \mathrm{~g}$ sodium chloride per kilogram [14]. Rats were fed with HFD for three weeks. On 21st or 22nd day streptozotocin dissolved in citric acid buffer ( $\mathrm{pH} \mathrm{4.0)}$ ) at a dosage of $35 \mathrm{mg} / \mathrm{kg}$ body weight bw/rat was administered intraperitoneally to induce diabetes. After 72 hours of STZ administration animals showing high blood glucose levels (>140 mg/dL) were considered as diabetic [15].

2.4. Experimental Plan. After the induction of diabetes, based on the body weight and blood glucose, the animals were divided into four groups consisting of four rats in each group. The experimental period was for 15 days.

Group I. Nondiabetic control rats received $300 \mu \mathrm{L}$ of safflower oil/kg bw/day.

Group II. Nondiabetic rats treated with $300 \mu \mathrm{g}$ of atrazine/kg bw/day suspended in safflower oil.

Group III. Diabetic control rats received $300 \mu \mathrm{L}$ of safflower oil/kg bw/day.

Group IV. Diabetic rats treated with $300 \mu \mathrm{g}$ of atrazine/kg bw/day suspended in safflower oil.

2.5. Evaluation of Sperm Parameters. Epididymal sperms were collected by chopping the epididymis in $5 \mathrm{~mL}$ of Ham's F-12 medium. The epididymal sperm viability and count was assessed according to WHO laboratory manual [16]. The sperm motility was analyzed by the method of Linder et al. [17] and Cooke et al. [18].

2.6. Evaluation of Blood Glucose Level and Antioxidant Activities. Blood glucose levels were determined by the kit method from Agappe Diagnostics Ltd, Kerala, India. Values were expressed as $\mathrm{mg} / \mathrm{dL}$. At the end of the treatment period, the rats were fasted overnight $(12 \mathrm{~h})$ and euthanized by cervical dislocation. Body weights were recorded prior to euthanization. The testes were dissected out, washed in icecold $1.15 \% \mathrm{KCl}$ solution, and pat-dried and wet weight was noted. Testis tissue homogenate $(10 \% \mathrm{w} / \mathrm{v})$ was prepared in phosphate buffer saline (PBS-pH 7.4) and centrifuged at $10000 \mathrm{~g}$ at $4^{\circ} \mathrm{C}$ for $15 \mathrm{~min}$. The supernatant was collected for assessing the activities of the antioxidant enzymes such as superoxide dismutase (SOD) activity by Marklund and Marklund method [19], Catalase (CAT) by Clairborne method [20], Glutathione peroxidase (GPx) by Rotruck et al. method [21], reduced glutathione (GSH) by Ellman method [22], and glutathione-S-transferase (GST) by Habig et al. method [23]; $\mathrm{H}_{2} \mathrm{O}_{2}$ generation was assayed by the method of Pick and Keisari [24] and the level of lipid peroxidation (LPO) product thiobarbituric acid (TBARS) by the method of Ohkawa et al. [25].

2.7. Evaluation of Steroidogenic Enzyme Activities. The activities of $3 \beta$-hydroxy steroid dehydrogenase ( $3 \beta$-HSD) and $17 \beta$ hydroxy steroid dehydrogenase (17 $\beta$-HSD) were measured by the method of Bergmeyer, [26] and the enzyme activities were expressed as nmol of NADPH converted into NADH per minute per milligram of protein.

2.8. Histological Examination. Testis were fixed in $10 \%$ neutral buffered formalin ( $\mathrm{pH} \mathrm{6.8)}$ and processed for histological examination by using routine paraffin-wax embedding method. Sections of $5 \mu \mathrm{m}$ were stained with hematoxylin and eosin.

2.9. Statistical Analysis. The results were expressed as mean \pm SD for four animals each group. Statistical analyses were performed by one-way analysis of variance (ANOVA) followed by Tukey's post testing using SPSS (SPSS 16.0, SPSS Inc. UK). $P \leq 0.05$ was considered as statistically significant.

\section{Results}

3.1. Effects of Atrazine on Body Weight and Testis Weight. The changes observed in the body weight and testis weight in groups II and IV were not significant when compared to group I and group III (Table 1), respectively.

3.2. Effects of Atrazine on Sperm Parameters. The changes observed in the sperm motility, viability, and count in groups II and IV were not significant when compared to group I and group III (Table 2 ), respectively.

3.3. Effects of Atrazine on Blood Glucose Level and Antioxidants in Testis of Normal and Diabetic Rats. Significant changes were observed in blood glucose levels in diabetic control and diabetic atrazine rats when compared to normal rats. However, no significant change in the blood glucose levels was observed between diabetic control and diabetic atrazine treated rats (Table 3 ). The changes observed in CAT, SOD, GPx, and GST activities in groups II and IV were not significant when compared to group I and group III (Table 3), respectively. The changes in the level of glutathione content 
TABLE 1: Effect of atrazine on body and testis weight.

\begin{tabular}{lcccc}
\hline Parameters & NC & NA & DC & DA \\
\hline Initial body weight & $163.33 \pm 05.77$ & $170.66 \pm 05.13$ & $140.00 \pm 08.75$ & $152.25 \pm 05.90$ \\
Final body weight & $242.33 \pm 14.90$ & $272.66 \pm 21.00$ & $193.25 \pm 18.82$ & $217.75 \pm 19.60$ \\
Testis weight & $1.22 \pm 0.11$ & $1.45 \pm 0.15$ & $1.2 \pm 0.22$ & $1.27 \pm 0.19$ \\
\hline
\end{tabular}

The data are represented as mean $\pm \mathrm{SD}(n=4)$ and evaluated by one-way analysis of variance (ANOVA) confirmed that the groups are not significantly differed $(P>0.05)$. NC: nondiabetic control rats, NA: nondiabetic atrazine treated rats, DC: diabetic control rats, and DA: diabetic atrazine treated rats.

TABLE 2: Effect of atrazine on sperm parameters.

\begin{tabular}{lcccc}
\hline Parameters & NC & NA & DC & DA \\
\hline Sperm count $\left(\times 10^{6}\right)$ & $79.40 \pm 06.45$ & $72.60 \pm 05.90$ & $60.50 \pm 04.71$ & $59.30 \pm 04.39$ \\
Sperm motility $(\%)$ & $89.73 \pm 06.37$ & $84.88 \pm 04.32$ & $69.78 \pm 05.98$ & $66.33 \pm 03.41$ \\
Viability $(\%)$ & $96.80 \pm 04.31$ & $89.11 \pm 05.03$ & $62.66 \pm 04.20$ & $63.69 \pm 04.31$ \\
\hline
\end{tabular}

The data are represented as mean $\pm \mathrm{SD}(n=4)$ and evaluated by one-way analysis of variance (ANOVA) confirmed that the groups are not significantly differed $(P>0.05)$. NC: nondiabetic control rats, NA: nondiabetic atrazine treated rats, DC: diabetic control rats, and DA: diabetic atrazine treated rats.

TABLE 3: Effect of atrazine on blood glucose levels and antioxidant status.

\begin{tabular}{lcccc}
\hline Parameters & NC & NA & DC & DA \\
\hline Blood glucose $^{\mathrm{a}}$ & $89.73 \pm 1.05$ & $90.89 \pm 3.04$ & $255.33 \pm 9.60$ & $268.67 \pm 2.89$ \\
CAT $^{\mathrm{b}}$ & $10.05 \pm 1.01$ & $8.30 \pm 0.87$ & $8.10 \pm 0.75$ & $7.90 \pm 0.78$ \\
SOD $^{\mathrm{c}}$ & $0.41 \pm 0.02$ & $0.36 \pm 0.01$ & $0.27 \pm 0.01$ & $0.28 \pm 0.01$ \\
$\mathrm{GPx}^{\mathrm{d}}$ & $12.17 \pm 1.11$ & $10.40 \pm 0.94$ & $8.00 \pm 0.69$ & $8.10 \pm 0.82$ \\
$\mathrm{GSH}^{\mathrm{e}}$ & $13.56 \pm 1.05$ & $11.03 \pm 1.02$ & $8.97 \pm 0.93$ & $8.40 \pm 0.85$ \\
$\mathrm{GST}^{\mathrm{f}}$ & $0.85 \pm 0.05$ & $0.72 \pm 0.03$ & $0.43 \pm 0.04$ & $0.40 \pm 0.03$ \\
\hline
\end{tabular}

The data are represented as mean $\pm \mathrm{SD}(n=4)$ and evaluated by one-way analysis of variance (ANOVA) confirmed by Tukey's test. Significant difference $(P<$ $0.05)$ is observed only in blood glucose levels of normal control and normal atrazine treated rats compared with diabetic control and diabetic atrazine treated rats, whereas the other parameters (CAT, SOD, GPx, GSH, and GST) are not significantly differed $(P>0.05)$. NC: nondiabetic control rats, NA: nondiabetic atrazine treated rats, DC: diabetic control rats, and DA: diabetic atrazine treated rats.

${ }^{\mathrm{a}} \mathrm{mg} / \mathrm{dL}$.

${ }^{\mathrm{b}} \mu \mathrm{M}$ of $\mathrm{H}_{2} \mathrm{O}_{2}$ consumed/min/mg protein.

$c_{\mathrm{mM}}$ pyrogallol oxidized $\mathrm{min} / \mathrm{mg}$ protein.

$\mathrm{d} \mu \mathrm{mol}$ of glutathione (GSH) utilized/min/mg protein.

${ }^{\mathrm{e}} \mu \mathrm{g} / \mathrm{dL}$.

${ }^{\mathrm{f}} \mu \mathrm{mol}$ of 1-chloro-2,4 dinitrobenzene (CDNB)-glutathione(GSH) conjugated/min/mg protein.

in groups II and IV were not significant when compared with group I and group III, respectively.

3.4. Effect of Atrazine on Lipid Peroxidation. The changes observed in groups II and IV were not significant when compared to group I and group III (Figure 1), respectively.

3.5. Effect of Atrazine on $\mathrm{H}_{2} \mathrm{O}_{2}$ Generation. $\mathrm{H}_{2} \mathrm{O}_{2}$ generation in groups II and IV was not significant (Figure 2) in comparison with group I and group III, respectively.

3.6. Effects of Atrazine on 3 $\beta$-HSD. The changes observed in $3 \beta$-HSD activity were not significant in group II and group IV when compared to group I and group III (Figure 3), respectively.

3.7. Effects of Atrazine on $17 \beta-H S D$. The changes observed in $17 \beta$-HSD activity were not significant in group II and group IV when compared to group I and group III (Figure 4), respectively.
3.8. Histological Findings. Group I, normal control rats (Figure 5(a)), shows normal spermatogonia, Sertoli cells, and Leydig cells with accumulation of spermatozoa within the seminiferous tubules. Group II shows normal atrazine treated rats (Figure 5(b)) which depicts normal spermatogonia, Sertoli cells, and Leydig cells with accumulation of spermatozoa within the seminiferous tubules. Group III, diabetic control rats (Figure 5(c)), illustrates reduced number of spermatogonia, Sertoli cells, and Leydig cells with drastic reduction of spermatozoa within the seminiferous tubules. Group IV, diabetic atrazine treated rats, shows (Figure 5(d)) reduced number of spermatogonia, Sertoli cells, and Leydig cells with drastic reduction of spermatozoa within the seminiferous tubules.

\section{Discussion}

No mortality and behavioral changes were observed in the experimental animals throughout the experimental period. Gain in the body weights was observed and it correlates with the previous reports [27-29]. The increased testes weight may be due to superficial changes because the absolute weight 


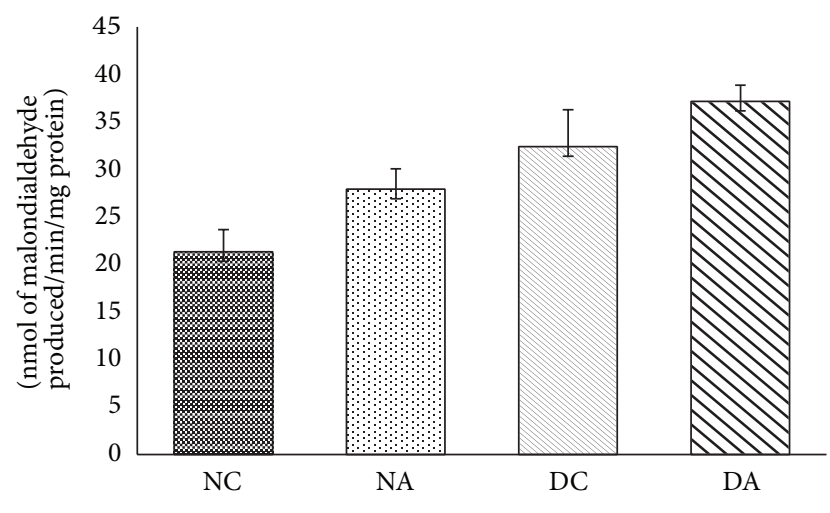

FIGURE 1: Effects of atrazine on lipid peroxidation. The data are represented as mean $\pm \mathrm{SD}(n=4)$ and evaluated by one-way analysis of variance (ANOVA) confirmed that the groups are not significantly differed $(P>0.05)$. NC $=$ nondiabetic control rats, $\mathrm{NA}=$ nondiabetic atrazine treated rats, $\mathrm{DC}=$ diabetic control rats, and $\mathrm{DA}=$ diabetic atrazine treated rats.

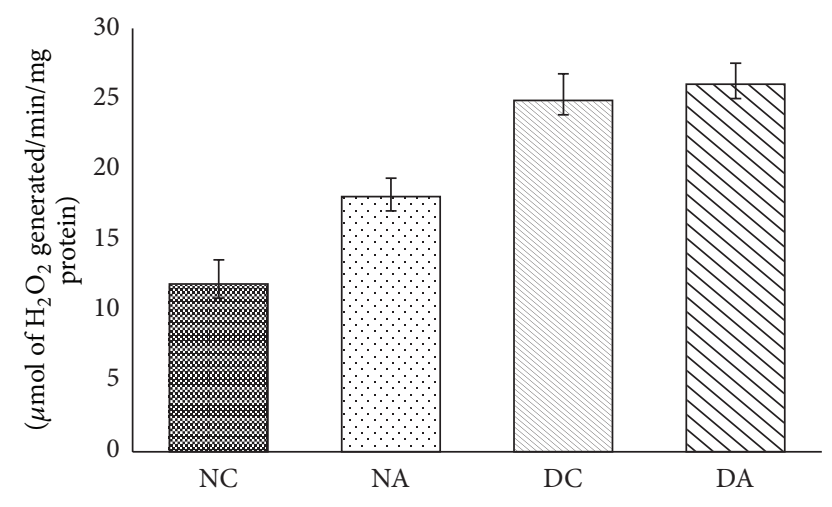

Figure 2: Effects of atrazine on $\mathrm{H}_{2} \mathrm{O}_{2}$ generation. The data are represented as mean $\pm \mathrm{SD}(n=4)$ and evaluated by one-way analysis of variance (ANOVA) confirmed that the groups are not significantly differed $(P>0.05) . \mathrm{NC}=$ nondiabetic control rats, $\mathrm{NA}=$ nondiabetic atrazine treated rats, $\mathrm{DC}=$ diabetic control rats, and $\mathrm{DA}=$ diabetic atrazine treated rats.

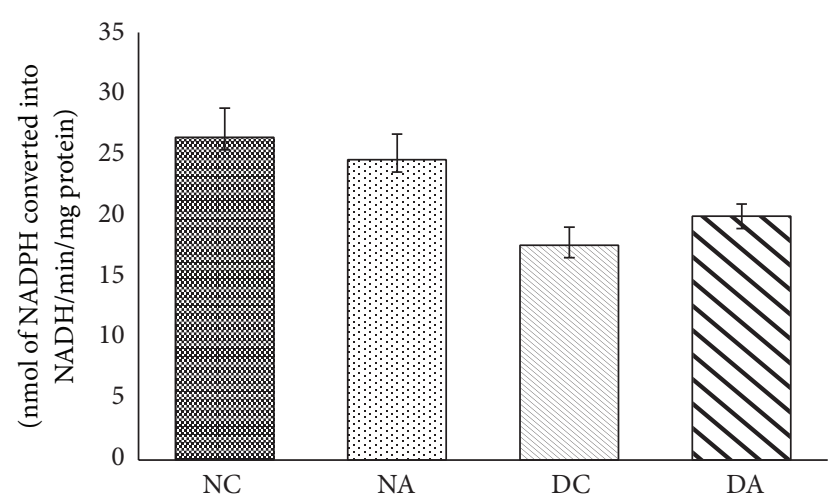

FIGURE 3: Effects of atrazine on $3 \beta$-HSD. The data are represented as mean $\pm \mathrm{SD}(n=4)$ and evaluated by one-way analysis of variance (ANOVA) confirmed that the groups are not significantly differed $(P>0.05) . \mathrm{NC}=$ nondiabetic control rats, $\mathrm{NA}=$ nondiabetic atrazine treated rats, $\mathrm{DC}=$ diabetic control rats, and $\mathrm{DA}=$ diabetic atrazine treated rats.

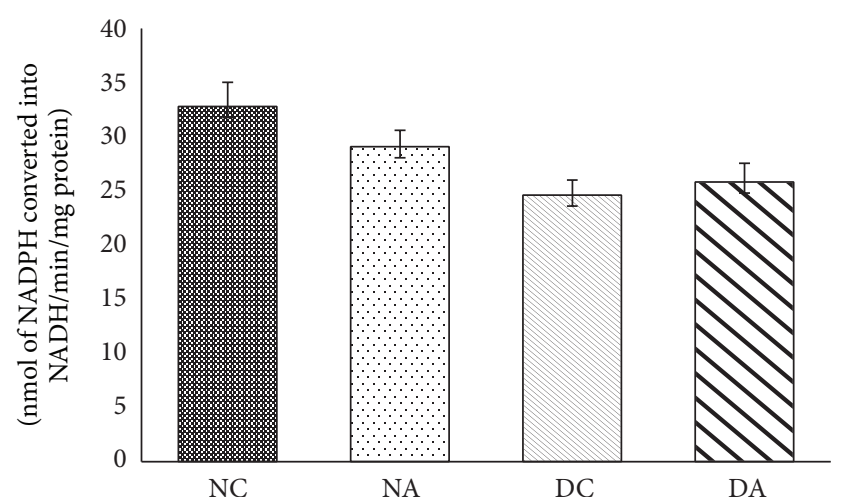

FIGURE 4: Effects of atrazine on $17 \beta$-HSD. The data are represented as mean $\pm \mathrm{SD}(n=4)$ and evaluated by one-way analysis of variance (ANOVA) confirmed that the groups are not significantly differed $(P>0.05) . \mathrm{NC}=$ nondiabetic control rats, $\mathrm{NA}=$ nondiabetic atrazine treated rats, $\mathrm{DC}=$ diabetic control rats, and $\mathrm{DA}=$ diabetic atrazine treated rats.

did not significantly differ from the control group. Increase in testicular weight was similar to the previous reports on toxicants that affect male reproductive health $[30,31]$.

Mammalian testis cell membranes are rich in poly unsaturated fatty acids (PUFA) and are sensitive to oxygen and nitrogen derived free radicals. Increased generation of reactive oxygen species (ROS) subjects the cell to oxidative stress and damages the cellular DNA, proteins, and lipids (lipid peroxidation) which leads to cell death $[32,33]$. Increased lipid peroxidation indicates increased generation of oxygen free radicals and it is associated with decreased sperm motility, viability, and count $[34,35]$. The increased level of lipid peroxidation and $\mathrm{H}_{2} \mathrm{O}_{2}$ reveals that atrazine affects spermatogenesis [36].

Significant changes were observed in blood glucose levels in diabetic control and diabetic atrazine rats when compared to normal rats. However, no significant change in the blood glucose levels was observed between diabetic control and diabetic atrazine treated rats. The study conducted by Lim et al. [37] with chronic administration of low dose of atrazine $300 \mu \mathrm{g} / \mathrm{kg}$ bw/day decreased basal metabolic rate and insulin resistance. Though the dosage was same, in the present study, no significant changes in blood glucose levels were observed in diabetic atrazine rats which may be due to short treatment period (15 days). ATZ has been shown to induce oxidative stress by producing ROS $[5,38]$. Exposure of experimental animals to pesticides is known to induce lipid peroxidation in various tissues, which is responsible for the adverse biological effects [39-41]. SOD converts superoxide radical into $\mathrm{H}_{2} \mathrm{O}_{2}$, which gets degraded by catalase and glutathione peroxidase/reductase system [42]. Reduced activities of SOD, CAT, and GPx in nondiabetic atrazine treated animals show an inability to eliminate superoxide radicals in testis. GSH plays an important role in protecting tissue from various xenobiotics induced injury [43]. But decreased levels of GSH were observed upon exposure to different pesticides $[44,45]$. An increased activity of GST suggests an increased production of reduced glutathione metabolites on exposure 


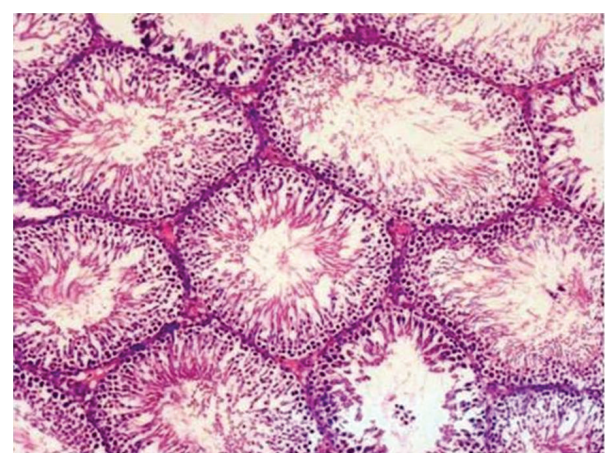

(a)

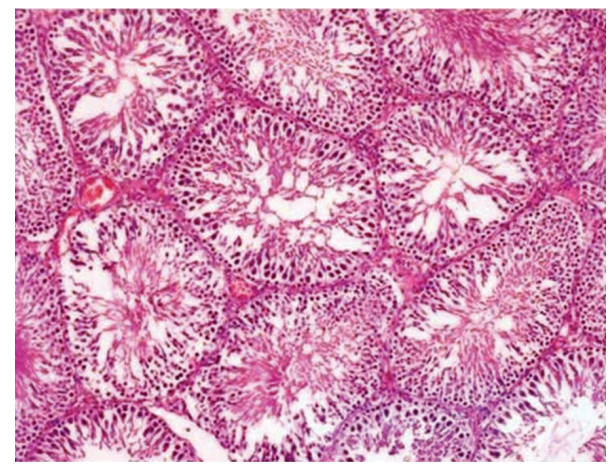

(c)

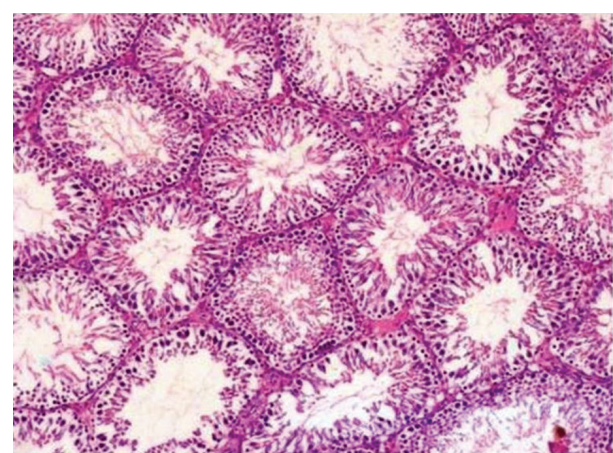

(b)

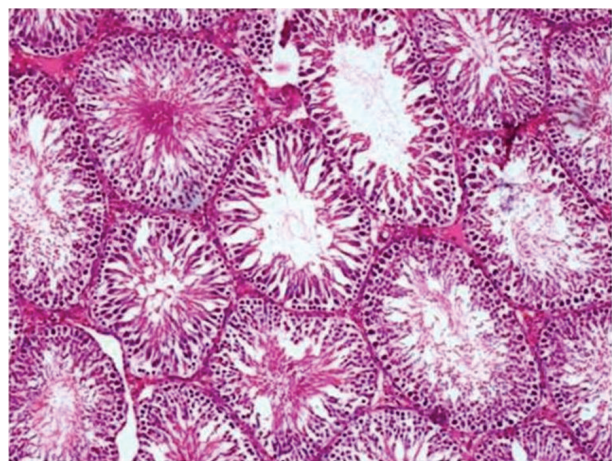

(d)

FIGURE 5: Light microscopic images of the section of testis. (a), (b), (c), and (d) are hematoxylin and eosin (H\&E 40x) stained section of testis of nondiabetic control (NC), nondiabetic atrazine treated rats (NA), diabetic control rats (DC), and diabetic atrazine treated rats (DA), respectively. (a) and (b) show normal spermatogonia, Sertoli cells, and Leydig cells with accumulation of spermatozoa within the seminiferous tubules. (c) and (d) show reduced numbers of spermatogonia, Sertoli cells, and Leydig cells with drastic reduction of spermatozoa within the seminiferous tubules.

to pesticides $[40,45]$. In the present study reduced GST activity in both nondiabetic atrazine treated rats and diabetic atrazine treated rats suggests that there is a reduction in reduced glutathione metabolites production. Nonsignificant elevated activities of SOD and GPx were observed in diabetic atrazine treated rats compared to diabetic control rats, which suggests that diabetic complications are not the same in each individual group or these elevated activities may be due to an increase in body weight and testicular weight in each group of animals.

The rate limiting step in steroidogenesis is translocation of cholesterol from outer membrane to inner membrane of mitochondria in testis. $3 \beta$-HSD and $17 \beta$-HSD play an important role in steroidogenesis. $3 \beta$-HSD converts dehydroepiandrosterone (DHEA) to androstenedione. $17 \beta-\mathrm{HSD}$ converts androstenedione to testosterone. The cytochrome $\mathrm{p} 450$ enzymes produce free radicals by formation of pseudosubstrate- $\mathrm{O}_{2}$ complex $[45,46]$ and these free radicals interact with steroid products. Increased production of $\mathrm{H}_{2} \mathrm{O}_{2}$ decreases activities of steroidogenic enzymes. Antiandrogenic effects of $\mathrm{H}_{2} \mathrm{O}_{2}$ were demonstrated in mouse Leydig tumor cells $[46,47]$. Increased free radical production is linked to reduced steroidogenesis. Reports are suggesting androgenic dehydrogenases are significantly inhibited by free radicals [48-51]. Exposure of atrazine at higher doses leds to reduced expressions of $3 \beta$-HSD and $17 \beta$-HSD genes [52]. In the present study reduction in $3 \beta$-HSD and $17 \beta$-HSD activities may be due to an increased production of $\mathrm{H}_{2} \mathrm{O}_{2}$. Increased activities of $3 \beta$-HSD and $17 \beta$-HSD in diabetic atrazine treated rats may be due to an increase in body weight and testis weight or may be due to decreased production of $\mathrm{H}_{2} \mathrm{O}_{2}$ and TBARS.

Normal control rats (Figure 5(a)-group I) reveal normal spermatogonia, Sertoli cells, and Leydig cells with accumulation of spermatozoa within the seminiferous tubules. Animals treated with atrazine at a dose of $120 \mathrm{mg} / \mathrm{Kg}$ bw showing reduction in Leydig cell size, irregular shapes, and degenerative changes were observed [53]. In the present study normal atrazine treated rats (Figure 5(b) - group II) show normal spermatogonia, Sertoli cells, and Leydig cells with accumulation of spermatozoa within the seminiferous tubules because the dosage of atrazine $(300 \mu \mathrm{g} / \mathrm{kg} \mathrm{bw})$ is very low. Experimentally induced diabetic rats show disturbed spermatogenesis, dilated seminiferous tubules, and decreased numbers of spermatogonium, primary spermatocytes, spermatids, and mature spermatozoa [54]. In this study, diabetic control rats (Figure 5(c) - group III) show reduced numbers of spermatogonia, Sertoli cells, and Leydig cells with drastic reduction of spermatozoa within the seminiferous tubules. Diabetic atrazine treated animals (Figure 5(d) - group IV) 
reveal reduced numbers of spermatogonia, Sertoli cells, and Leydig cells with drastic reduction of spermatozoa within the seminiferous tubules; this group was showing histology similar to diabetic control because the dosage of atrazine $(300 \mu \mathrm{g} /$ $\mathrm{kg}$ ) is very low.

In conclusion exposure to atrazine at a dosage of $300 \mu \mathrm{g} /$ $\mathrm{kg}$ body weight has no significant effects on blood glucose levels, testicular antioxidant status, sperm functions, and steroidogenic enzyme activities and histology also reveals that atrazine at a dosage of $300 \mu \mathrm{g} / \mathrm{kg}$ body weight does not acquire reproductive toxicity. To know the effects of atrazine in diabetic rats further studies have to be carried out with increased concentration of atrazine.

\section{Conflict of Interests}

The authors declare that there is no conflict of interests regarding the publication of this paper.

\section{Acknowledgment}

This work has been funded by UGC-SAP (Grant no. F330/2011).

\section{References}

[1] J. Toppari, J. C. Larsen, P. Christiansen et al., "Male reproductive health and environmental xenoestrogens," Environmental Health Perspectives, vol. 104, no. 4, pp. 741-803, 1996.

[2] A. G. Frenich, P. P. Bolaños, and J. L. M. Vidal, "Multiresidue analysis of pesticides in animal liver by gas chromatography using triple quadrupole tandem mass spectrometry," Journal of Chromatography A, vol. 1153, no. 1-2, pp. 194-202, 2007.

[3] S. S. Caldas, A. Demoliner, F. P. Costa, M. G. M. D'Oca, and E. G. Primel, "Pesticide residue determination in groundwater using solid-phase extraction and high-performance liquid chromatography with diode array detector and liquid chromatography-tandem mass spectrometry," Journal of the Brazilian Chemical Society, vol. 21, no. 4, pp. 642-650, 2010.

[4] T. Hayes, K. Haston, M. Tsui, H. Hoang, C. Haeffele, and A. Vonk, "Atrazine-induced hermaphroditism at $0.1 \mathrm{ppb}$ in American leopard frogs (Rana pipiens): laboratory and field evidence," Environmental Health Perspectives, vol. 111, no. 4, pp. 568-575, 2003.

[5] S. O. Abarikwu, A. C. Adesiyan, T. O. Oyeloja, M. O. Oyeyemi, and E. O. Farombi, "Changes in sperm characteristics and induction of oxidative stress in the testis and epididymis of experimental rats by a herbicide, atrazine," Archives of Environmental Contamination and Toxicology, vol. 58, no. 3, pp. 874$882,2010$.

[6] D. Sajad-Feyzi, M. Hassan, S. Rasool, and S. Rajab-Ali, "Detrimental effect of atrazine on testicular tissue and sperm quality: implication for oxidative stress and hormonal alterations," Iranian Journal of Toxicology, vol. 5, no. 1-2, pp. 426-435, 2011.

[7] M. Mokhtar, S. Esfandiar, and S. Amrola, "The effects of atrazine on levels of pituitary-testis hormones in adult male rat," Egyptian Academic Journal of Biological Sciences, vol. 2, no. 2, pp. 53-60, 2010.
[8] A. B. Olokoba, O. A. Obateru, and L. B. Olokoba, "Type 2 diabetes mellitus: a review of current trends," Oman Medical Journal, vol. 27, no. 4, pp. 269-273, 2012.

[9] L. Chen, D. J. Magliano, and P. Z. Zimmet, "The worldwide epidemiology of type 2 diabetes mellitus-present and future perspectives," Nature Reviews Endocrinology, vol. 8, no. 4, pp. 228-236, 2012.

[10] A. Ramachandran, A. K. Das, S. R. Joshi, C. S. Yajnik, S. Shah, and K. M. P. Kumar, "Current status of diabetes in India and need for novel therapeutic agents," Journal of Association of Physicians of India, vol. 58, pp. 7-9, 2010.

[11] M. D. Girón, R. Salto, Y. González et al., "Modulation of hepatic and intestinal Glutathione S-transferases and other antioxidant enzymes by dietary lipids in streptozotocin diabetic rats," Chemosphere, vol. 38, no. 13, pp. 3003-3013, 1999.

[12] N. F. Wiernsperger, "Oxidative stress: the special case of diabetes," BioFactors, vol. 19, no. 1-2, pp. 11-18, 2003.

[13] D. Kianifard, R. A. Sadrkhanlou, and S. Hasanzadeh, "The ultrastructural changes of the sertoli and leydig cells following streptozotocin induced diabetes," Iranian Journal of Basic Medical Sciences, vol. 15, no. 1, pp. 623-635, 2012.

[14] M. K. Sangeetha, H. R. Balaji Raghavendran, V. Gayathri, and H. R. Vasanthi, "Tinospora cordifolia attenuates oxidative stress and distorted carbohydrate metabolism in experimentally induced type 2 diabetes in rats," Journal of Natural Medicines, vol. 65, no. 3-4, pp. 544-550, 2011.

[15] K. Srinivasan, B. Viswanad, L. Asrat, C. L. Kaul, and P. Ramarao, "Combination of high-fat diet-fed and low-dose streptozotocintreated rat: a model for type 2 diabetes and pharmacological screening," Pharmacological Research, vol. 52, pp. 313-320, 2005.

[16] WHO, WHO Laboratory Manual for the Examination of Human Semen and Sperm-Cervical Mucus interactions, WHO, 4th edition, 1999.

[17] R. E. Linder, L. F. Strader, and W. K. McElroy, "Measurement of epididymal sperm motility as a test variable in the rat," Bulletin of Environmental Contamination and Toxicology, vol. 36, no. 3, pp. 317-324, 1986.

[18] P. S. Cooke, P. Young, R. A. Hess, and G. R. Cunha, "Estrogen receptor expression in developing epididymis, efferent ductules, and other male reproductive organs," Endocrinology, vol. 128, no. 6, pp. 2874-2879, 1991.

[19] S. Marklund and G. Marklund, "Involvement of the superoxide anion radical in the autoxidation of pyrogallol and a convenient assay for superoxide dismutase," European Journal of Biochemistry, vol. 47, no. 3, pp. 469-474, 1974.

[20] A. Claiborne, "Catalase activity," in CRC Handbook of Methods for Oxygen Radical Research, R. A. Greenwald, Ed., pp. 283-284, CRC Press, Boca Raton, Fla, USA, 1985.

[21] J. T. Rotruck, A. L. Pope, H. E. Ganther, A. B. Swanson, D. G. Hafeman, and W. G. Hoekstra, "Selenium: biochemical role as a component of glatathione peroxidase," Science, vol. 179, no. 4073, pp. 588-590, 1973.

[22] G. L. Ellman, "Tissue sulfhydryl groups," Archives of Biochemistry and Biophysics, vol. 82, no. 1, pp. 70-77, 1959.

[23] W. H. Habig, M. J. Pabst, and W. B. Jakoby, "Glutathione S transferases: the first enzymatic step in mercapturic acid formation," The Journal of Biological Chemistry, vol. 249, no. 22, pp. 71307139, 1974.

[24] E. Pick and Y. Keisari, "Superoxide anion and hydrogen peroxide production by chemically elicited peritoneal macrophagesinduction by multiple nonphagocytic stimuli," Cellular Immunology, vol. 59, no. 2, pp. 301-318, 1981. 
[25] H. Ohkawa, N. Ohishi, and K. Yagi, "Assay for lipid peroxides in animal tissues by thiobarbituric acid reaction," Analytical Biochemistry, vol. 95, no. 2, pp. 351-358, 1979.

[26] H. U. Bergmeyer, "Hydroxysteroid dehydrogenase," in Methods of Enzymatic Analysis, pp. 447-489, Academic Press, New York, NY, USA, 1974.

[27] C. Cantemir, C. Cozmei, B. Scutaru, S. Nicoara, and E. Carasevici, "p53 Protein expression in peripheral lymphocytes from atrazine chronically intoxicated rats," Toxicology Letters, vol. 93, no. 2-3, pp. 87-94, 1997.

[28] H. Kandori, S. Suzuki, M. Asamoto et al., "Influence of atrazine administration and reduction of calorie intake on prostate carcinogenesis in probasin/SV40 T antigen transgenic rats," Cancer Science, vol. 96, no. 4, pp. 221-226, 2005.

[29] K. Fukamachi, B. Seok Han, C. Kyu Kim et al., "Possible enhancing effects of atrazine and nonylphenol on 7,12-dimethylbenz[a]anthracene-induced mammary tumor development in human c-Ha-ras proto-oncogene transgenic rats," Cancer Science, vol. 95, no. 5, pp. 404-410, 2004.

[30] M. Nakai, R. A. Hess, B. J. Moore, R. F. Guttroff, L. F. Strader, and R. E. Linder, "Acute and long-term effects of a single dose of the fungicide carbendazim (methyl 2-benzimidazole carbamate) on the male reproductive system in the rat," Journal of Andrology, vol. 13, no. 6, pp. 507-518, 1992.

[31] R. A. Hess, "Effects of environmental toxicants on the efferent ducts, epididymis and fertility," Journal of Reproductive Fertility, Supplement, vol. 53, pp. 247-259, 1998.

[32] A. Agarwal, S. Gupta, and S. Sikka, "The role of free radicals and antioxidants in reproduction," Current Opinion in Obstetrics and Gynecology, vol. 18, no. 3, pp. 325-332, 2006.

[33] K. J. A. Davies, "The broad spectrum of responses to oxidants in proliferating cells: a new paradigm for oxidative stress," International Union of Biochemistry and Molecular Biology Life, vol. 48, no. 1, pp. 41-47, 1999.

[34] J. J. Thiele, H. J. Freislebeb, J. Fuchs, and F. R. Ochsendorf, "Ascorbic acid and urate in human seminal plasma: determination and interrelationships with chemiluminescence in washed semen," Human Reproduction, vol. 10, no. 1, pp. 110-115, 1995.

[35] G. Najafi, M. Razi, A. Hoshyar, S. Shahmohamadloo, and S. Feyzi, "The effect of chronic exposure with imidacloprid insecticide on fertility in mature male rats," International Journal of Fertility and Sterility, vol. 4, no. 1, pp. 9-16, 2010.

[36] J. G. Alvarez, J. C. Touchstone, L. Blasco, and B. T. Storey, "Spontaneous lipid peroxidation and production of hydrogen peroxide and superoxide in human spermatozoa. Superoxide dismutase as major enzyme protectant against oxygen toxicity.", Journal of Andrology, vol. 8, no. 5, pp. 338-348, 1987.

[37] S. Lim, S. Y. Ahn, I. C. Song et al., "Chronic exposure to the herbicide, atrazine, causes mitochondrial dysfunction and insulin resistance," PLoS ONE, vol. 4, no. 4, Article ID e5186, 2009.

[38] S. O. Abarikwu, E. O. Farombi, M. P. Kashyap, and A. B. Pant, "Kolaviron protects apoptotic cell death in PC12 cells exposed to atrazine," Free Radical Research, vol. 45, no. 9, pp. 1061-1073, 2011.

[39] Y. Sharma, S. Bashir, M. Irshad, T. C. Nag, and T. D. Dogra, "Dimethoate-induced effects on antioxidant status of liver and brain of rats following subchronic exposure," Toxicology, vol. 215, no. 3, pp. 173-181, 2005.

[40] F. M. El-Demerdash, M. I. Yousef, F. S. Kedwany, and H. H. Baghdadi, "Role of $\alpha$-tocopherol and $\beta$-carotene in ameliorating the fenvalerate-induced changes in oxidative stress, hemato-biochemical parameters, and semen quality of male rats," Journal of Environmental Science and Health, vol. 39, no. 3, pp. 443-459, 2004.

[41] A. Kamboj, R. Kiran, and R. Sandhir, "Carbofuran-induced neurochemical and neurobehavioral alterations in rats: attenuation by N-acetylcysteine," Experimental Brain Research, vol. 170, no. 4, pp. 567-575, 2006.

[42] J. G. Alvarez and B. T. Storey, "Role of glutathione peroxidase in protecting mammalian spermatozoa from loss of motility caused by spontaneous lipid peroxidation," Gamete Research, vol. 23, no. 1, pp. 77-90, 1989.

[43] G. Wu, Y.-Z. Fang, S. Yang, J. R. Lupton, and N. D. Turner, "Glutathione metabolism and its implications for health," Journal of Nutrition, vol. 134, no. 3, pp. 489-492, 2004.

[44] A. Thapar, R. Sandhir, and R. Kiran, "Acephate induced oxidative damage in erythrocytes," Indian Journal of Experimental Biology, vol. 40, no. 8, pp. 963-966, 2002.

[45] M. Singh, R. Sandhir, and R. Kiran, "Erythrocyte antioxidant enzymes in toxicological evaluation of commonly used organophosphate pesticides," Indian Journal of Experimental Biology, vol. 44, no. 7, pp. 580-583, 2006.

[46] T. Endo, R. F. Aten, L. Leykin, and H. R. Behrman, "Hydrogen peroxide evokes antisteroidogenic and antigonadotropic actions in human granulosa luteal cells," The Journal of Clinical Endocrinology and Metabolism, vol. 76, no. 2, pp. 337-342, 1993.

[47] D. M. Stocco, J. Wells, and B. J. Clark, "The effects of hydrogen peroxide on steroidogenesis in mouse Leydig tumor cells," Endocrinology, vol. 133, no. 6, pp. 2827-2832, 1993.

[48] C. Latchoumycandane, K. C. Chitra, and P. P. Mathur, "The effect of 2,3,7,8-tetrachlorodibenzo-p-dioxin on the antioxidant system in mitochondrial and microsomal fractions of rat testis," Toxicology, vol. 171, no. 2-3, pp. 127-135, 2002.

[49] C. Latchoumycandane and P. P. Mathur, "Effect of methoxychlor on the antioxidant system in mitochondrial and microsomerich fractions of rat testis," Toxicology, vol. 176, no. 1-2, pp. 67-75, 2002.

[50] K. C. Chitra, C. Latchoumycandane, and P. P. Mathur, "Induction of oxidative stress by bisphenol A in the epididymal sperm of rats," Toxicology, vol. 185, no. 1-2, pp. 119-127, 2003.

[51] P. Murugesan, J. Senthilkumar, K. Balasubramanian, M. M. Aruldhas, and J. Arunakaran, "Impact of polychlorinated biphenyl Aroclor 1254 on testicular antioxidant system in adult rats," Human and Experimental Toxicology, vol. 24, no. 2, pp. 6166, 2005.

[52] K. Pogrmic, S. Fa, V. Dakic, S. Kaisarevic, and R. Kovacevic, "Atrazine oral exposure of peripubertal male rats downregulates steroidogenesis gene expression in Leydig cells," Toxicological Sciences, vol. 111, no. 1, pp. 189-197, 2009.

[53] J. Kniewald, M. Jakominic, A. Tomljenovic et al., "Disorders of male rat reproductive tract under the influence of atrazine," Journal of Applied Toxicology, vol. 20, no. 1, pp. 61-68, 2000.

[54] S.-L. Feng, S.-H. Li, Y. Wang, C.-C. Chen, and B. Gao, "Effect of ligustrum fruit extract on reproduction in experimental diabetic rats," Asian Journal of Andrology, vol. 3, no. 1, pp. 7173, 2001. 

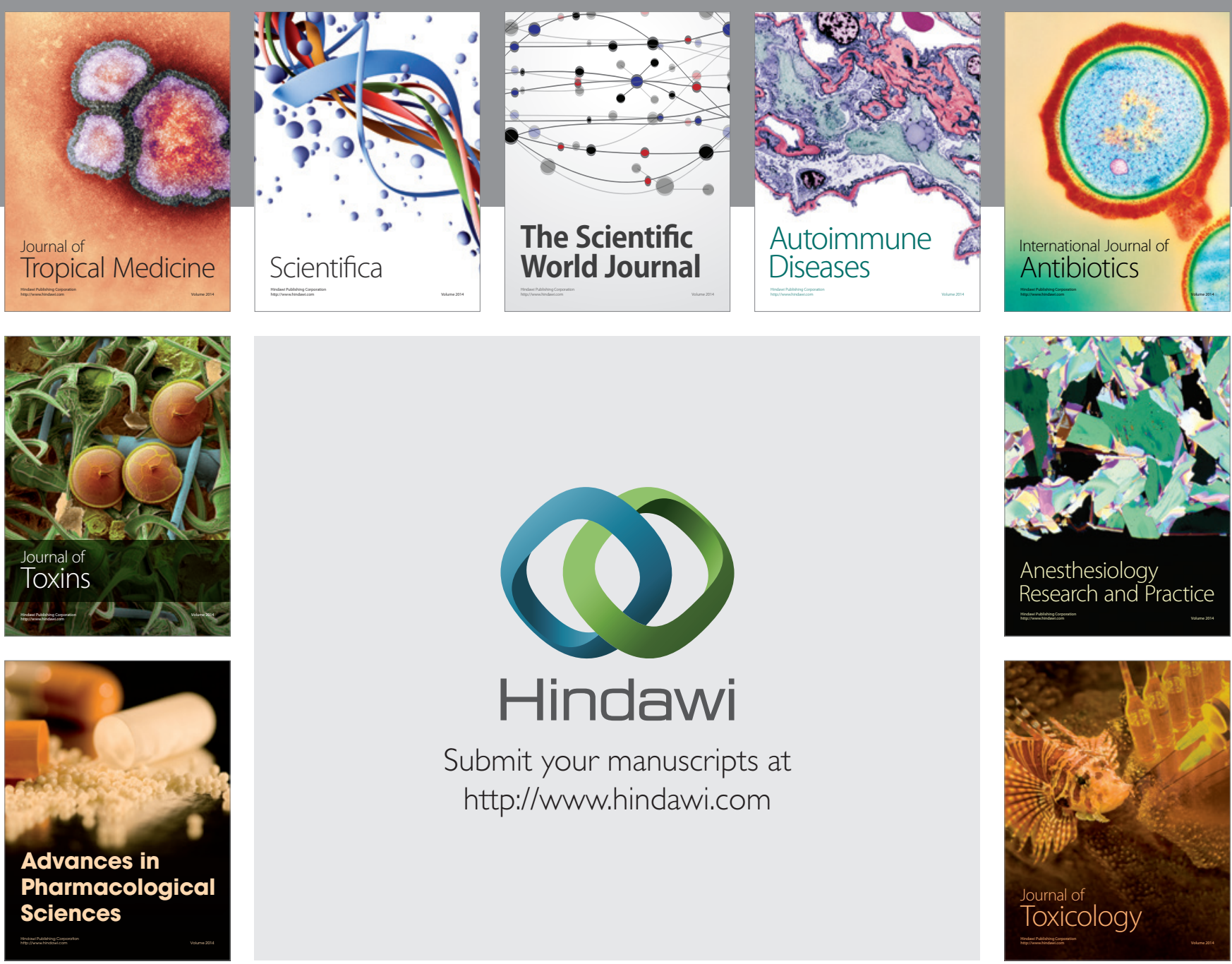

\section{Hindawi}

Submit your manuscripts at

http://www.hindawi.com
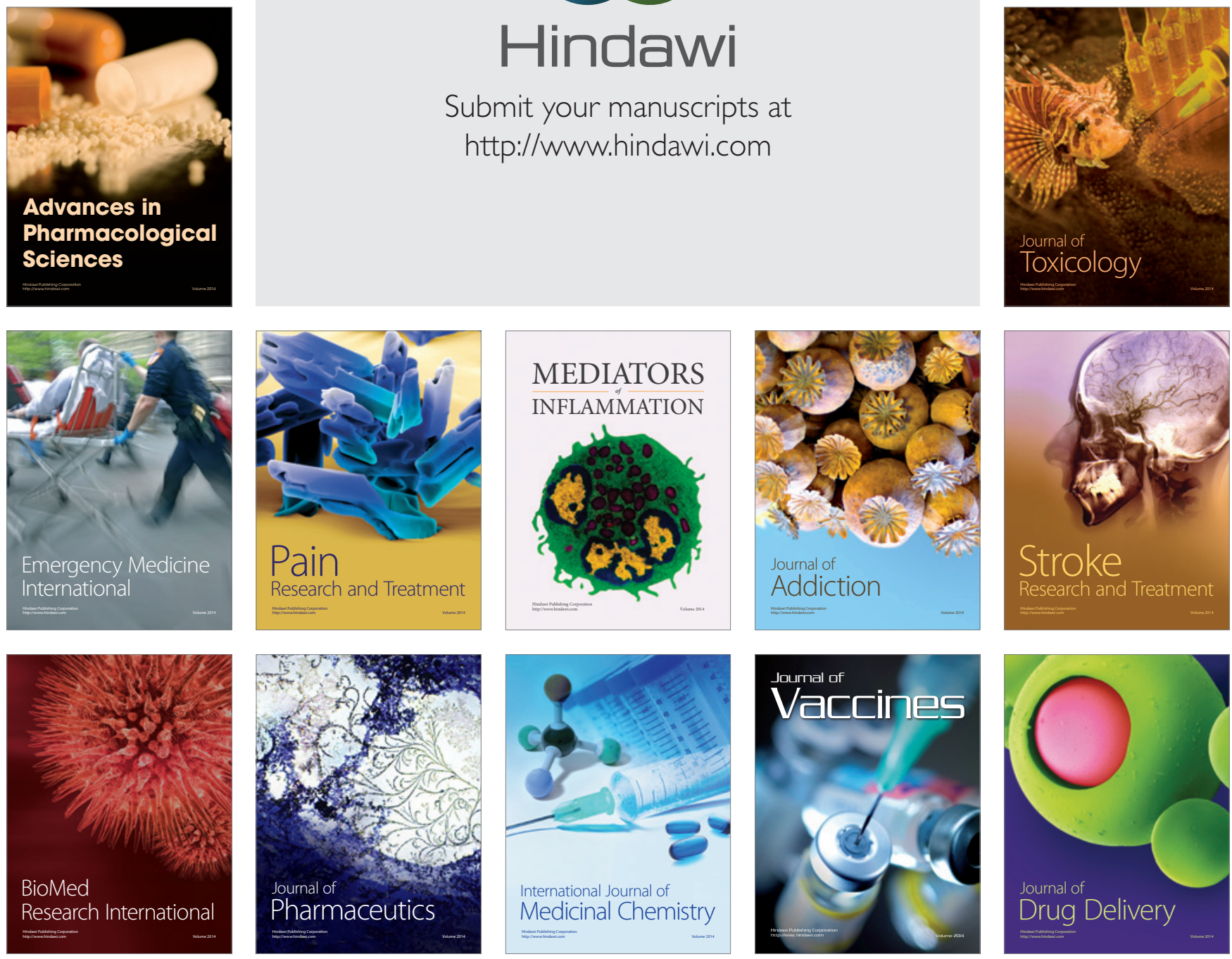